\title{
VIOLÊNCIA DOMÉSTICA NO ESTADO DE MATO GROSSO DO SUL: O CONTEXTO DA PANDEMIA DE COVID-19 NO ANO DE 2020
}

\section{DOMESTIC VIOLENCE IN THE STATE OF MATO GROSSO DO SUL: THE CONTEXT OF THE COVID-19 PANDEMIC IN THE YEAR 2020}

\author{
Vitória de Jesus \\ Acadêmica do curso de Licenciatura em Geografia, PIVIC/CPAQ/UFMS \\ v.jesus@ufms.br
}

Eva Teixeira dos Santos

Docente dos Cursos de Graduação e Pós-Graduação em Geografia, Campus de Aquidauana - UFMS eva.teixeira@ufms.br

\begin{abstract}
RESUMO
Entendendo que, anualmente, se nota um aumento dos casos de agressão à mulher, o presente trabalho tem por objetivo evidenciar como os casos de violência doméstica vem ocorrendo em contexto de pandemia, sobretudo na condição específica de isolamento desencadeado pelas fases restritivas no estado de Mato Grosso do Sul no ano de 2020. Como muitos dos casos em que ocorre violência contra a mulher geralmente se possuí o vínculo parental ou matrimonial entre agressor e vítima, se busca compreender como ocorre o acréscimo desses casos e onde há o maior foco do fenômeno no recorte espacial estudado. Fora isso se busca compreender o desfecho dos casos, como prisão do agressor ou concretização do feminicídio, e a forma de obtenção de ajuda em período específico de quarentena e isolamento social.
\end{abstract}

Palavras-Chave: Feminicídio. Pandemia. Quarentena.

\begin{abstract}
Understanding that, annually, there is an increase in the cases of aggression against women, the present study aims to show how the cases of domestic violence it has been occurring in the context of a pandemic, especially in the specific condition of isolation triggered by the restrictive phases in the state of Mato Grosso do Sul in 2020. Like many of the cases where violence against women occurs, there is usually a parental or marital bond between the aggressor and the victim, it seeks to understand how these cases increase and where there is the greatest focus of the phenomenon in the studied spatial profile. Other than that, the aim is to understand the outcome of the cases, such as the arrest of the aggressor or the implementation of femicide, and how to obtain help during a specific period of quarantine and social isolation.
\end{abstract}

Keywords: Femicide Pandemic. Quarantine.

\section{INTRODUÇÃO}

A pandemia do coronavírus (SARS-CoV-2), ao se espacializar além da cidade de Wuhan, China, que catalogou o primeiro caso em dezembro de 2019, avançou para diferentes países incluindo o Brasil que apresentou seu primeiro caso no estado de São Paulo em fevereiro em 2020 (SANAR SAÚDE, 2020).

O avanço da transmissão comunitária forçou com que a Organização Mundial da Saúde (OMS) traçasse estratégias de contenção dos casos a partir de medidas como isolamento de casos suspeitos e distanciamento social para evitar a contração. A fim de evitar um aumento exponencial dos casos e da sobrecarga dos serviços de saúde, se notou, em contrapartida, um aumento dos casos de violência doméstica.

Recebido em: 10/01/2022

Aceito para publicação em: 27/01/2022.

$\begin{array}{lllll}\text { Hygeia } & \text { Uberlândia - MG } \quad \text { Edição especial: X GeoSaude } \quad \text { Fev./2022 } & \text { p. 61-73 } & \text { Página } 61\end{array}$


De acordo com o artigo $5^{\circ}$ da Lei Maria da Penha (Lei n. 11.340/06), violência doméstica é definida como "qualquer ação ou omissão baseada no gênero que lhe cause morte, lesão, ação ou omissão baseada no gênero que lhe cause morte, lesão, sofrimento físico, sexual ou psicológico e dano moral ou patrimonial" (BRASIL, 2006).

Em 2020, segundo o Ministério da Mulher, da Família e dos Direitos Humanos, foram registradas 105.821 denúncias de violência contra a mulher através do Ligue 180 e do Disque 100. O número representa um chamado a cada 5 minutos. Apesar de possuir uma das três melhores legislações do mundo na proteção às mulheres em situação de violência, de acordo com dados do Alto Comissariado das Nações Unidades para os Direitos Humanos (ACHUDH), o Brasil permanece na $5^{a}$ posição no ranking de países com maior número de mortes violentas contra mulheres por questões de gênero. $O$ país só perde para El Salvador, Colômbia, Guatemala e Rússia em número de casos de assassinato de mulheres. Em comparação com países desenvolvidos, aqui se mata 48 vezes mais mulheres que o Reino Unido, 24 vezes mais que a Dinamarca e 16 vezes mais que o Japão ou Escócia (MATO GROSSO DO SUL, 2021).

Assim, para ser catalogado como tal deve ter ocorrência em casas, no ambiente doméstico ou onde se haja relação de familiaridade, afetividade ou coabitação. De acordo com Lobo (2020, p. 22), estes números registraram aumento, principalmente no que se refere aos atendimentos à violência doméstica pela Polícia Militar.

Em abril, pouco mais de trinta dias após o início das medidas protetivas destinadas a conter a disseminação da COVID-19, o Fórum Brasileiro de Segurança Pública (FBSP) emitiu uma nota técnica na qual apura, tomando os meses de março e abril deste ano [2020], um decréscimo nos registros de boletins de ocorrência em torno de crimes contra a mulher; registros esses que exigem a presença das vítimas. Por outro lado, foram documentados aumentos nos índices de atendimento à violência doméstica pela Polícia Militar e, também, nos números de feminicídio, tomando o mesmo período em 2019 como comparação.

Tal fato foi identificado no Anuário Brasileiro de Segurança Pública (2021, p. 96) conforme figura 1, onde $95,4 \%$ dos agressores são compostos por companheiros/ex-companheiros, parente e conhecido. No Mato Grosso do Sul, $80 \%$ dos autores do crime são conviventes ou ex-conviventes, como namorados ou maridos (MATO GROSSO DO SUL, 2021, p. 16). Assim se reforça o ponto que afirma que, com a implementação do isolamento social e quarenta, as mulheres se encontram mais expostas às situações de violência doméstica e feminicídio.

Figura 1: Feminicídios e demais mortes violentas intencionais de mulheres, por relação entre vítima e autor Brasil (2020).



Fonte: Secretarias Estaduais de Segurança Pública e/ou Defesa Social; Fórum Brasileiro de Segurança Pública.

Segundo Galvani (2020), o canal de denúncias denominado Ligue 180, como a Central de Atendimento à Mulher administrado pelo governo federal, a Secretaria Nacional de Políticas para Mulheres anunciou um aumento de $17 \%$ dos casos de denúncia registradas pela plataforma num comparativo entre o

\begin{tabular}{llllll}
\hline Hygeia Uberlândia - MG & Edição especial: X GeoSaude & Fev./2022 & p. 61-73 Página 62
\end{tabular}


começo e o fim de março, que também foi o período marcado por tais determinações de afastamento social no país.

De acordo com Marques et. al (2020, p. 1):

Instituições que compõem a rede de proteção a mulheres, crianças e adolescentes no Brasil também denunciam o aumento do número de casos e chamam a atenção para a possibilidade de menor visibilidade das situações em função da recomendação de se permanecer em casa, além do fechamento ou redução da jornada de trabalho dos serviços de proteção, tais como a delegacia de mulheres, conselhos tutelares etc.

Tais restrições de movimento pelas regras de distanciamento social, segundo Jesus e Santos (2020, p 20-21), ocasionou em um quadro onde "muitas mulheres - que já viviam em um relacionamento abusivo - [vissem] a situação se agravar, pois, se encontram em quarentena com seu agressor". Inclusive a quarentena também reduziu uma base social de apoio para sair da situação de violência e passou a se ver em contato quase que exclusivo ao seu agressor.

Na questão específica do Estado, segundo Alves (2020), o Ministério Público de Mato Grosso do Sul, apontou um aumento na quantidade de denúncias de violência contra a mulher oferecidas pela $47^{a}$, 48 ${ }^{\mathrm{a}}, 65^{\mathrm{a}}$ e $66^{\mathrm{a}}$ Promotorias de Justiça de Campo Grande. No total, se houve 565 denúncias entre meados do mês de março até o final do mês de julho de 2020. Também se registrou 942 atendimentos na Casa da Mulher Brasileira de Campo Grande.

Avançando o quadro de violência doméstica, a mídia Dossiê Violência Contra as Mulheres, aponta que "o feminicídio representa a última etapa de um continuum de violência que leva à morte" (BANDEIRA, 2013, p. 1).

Ademais, Tente e Machado (2020), ressaltam que somente nos três primeiros meses de 2020 se foram registrados 8 casos de feminicídios consumados e quase 4.500 B.O's registrados. Nesse caso, ressalta-se que feminicídio pode ser compreendido como o "homicídio cometido contra mulheres que é motivado por violência doméstica ou discriminação de gênero", segundo a Lei do Feminicídio n. 13.104/15 (BRASIL, 2015).

Inclusive, Mato Grosso do Sul registrou entre janeiro e novembro de 2020, 32 casos de feminicídio e 4.482 casos de violência doméstica (QUIRINO, 2020).

Devido ao fato, no dia 10 de dezembro de 2020, o governador Reinaldo Azambuja sanciona a Lei $\mathrm{n}$. 5.613 onde,

Art. 1ํ O Estado de Mato Grosso do Sul implementará medidas eficazes para prevenção da COVID-19 e para a maior proteção às mulheres e crianças vítimas de violência doméstica, durante o período de estado de calamidade, decretado em razão da pandemia de COVID-19 (DOE-MS, 2020).

Suas medidas consistem na divulgação de canais de denúncias bem como a disponibilização de canais de informação e orientação como direitos, formas de denúncia e órgãos de atendimento. Se há, sobretudo, a instituição de programas para proteção às mulheres em situação atual de violência doméstica, especialmente àquelas que se encontram em casos de medidas protetivas de urgência ao mesmo tempo em que se dissemina informações sobre iniciativas de higiene, prevenção e proteção de contágio e transmissão do vírus da COVID-19.

Um fenômeno observado segundo Tente (2020) é a contradição conforme o aumento de casos de violência doméstica e o decréscimo da formulação de B.O's que não acompanham o ritmo acelerado. A própria aponta a cidade de Dourados que teve uma queda de $3,5 \%$ de notificação de boletim de ocorrência na Delegacia de Atendimento à Mulher entre agosto de 2019 e 2020, mas que apresentou um aumento dos autos de prisão em flagrante aonde somente nos dez primeiros dias de setembro de 2020 houve 13 casos de prisões em flagrante, quase o dobro do ano anterior.

Pode-se, dessa forma, deduzir também que não se houve necessariamente a redução dos níveis de violência doméstica, sexual e de feminicídio no primeiro semestre do ano de 2020. É possível perceber que com a espacialização do COVID-19 e o maior respeito da população perante as medidas restritivas nos primeiros meses de imposição do isolamento social, houve um decréscimo da mobilidade social e nova adequação de serviços públicos para o atendimento não-presencial, dificultando a procura por ajuda.

Uma informação que sustenta a teoria é disponibilizada pelo Fórum Brasileiro de Segurança Pública (2021, p. 94) demonstrando que, em nível nacional, houve um aumento de 4,4\% de Medidas Protetivas

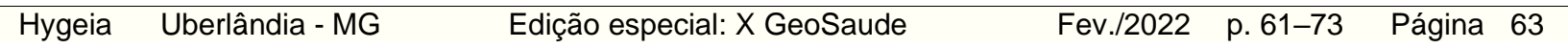


de Urgência (MPU) concedidas pelos Tribunais de Justiça e de 16,3\% de chamadas às Polícias Militares ao 190 por motivos de violência doméstica.

Isso se justifica a partir do fato de que se há maior empecilhos para a formulação do registro por parte das mulheres uma vez que se há pouco ou nenhum contato exterior e vigília integral do agressor. Por esse motivo, o governo do estado divulgou mecanismos para o incentivo às denúncias tais como a campanha do Sinal Vermelho.

Também se notou um aumento da subnotificação, como uma notificação deficiente, incompleta ou interrompida, também devido à dificuldade em dar continuidade ao processo de registros e à maior fiscalização por parte de seu agressor (BELCHIOR; MACHADO, 2020).

A anormalidade da queda de registros se estende também às notificações contra os casos de violência sexual, onde de acordo com FÓRUM... (2020, p. 111).

\begin{abstract}
É difícil saber, por ora, os impactos provocados pela pandemia de COVID-19 na vida de milhares de pessoas expostas à violência sexual, o que inclui o acesso a serviços de saúde e à justiça, mas os dados disponíveis indicam que houve queda expressiva das notificações criminais nos primeiros meses de isolamento social. Os registros, que se mantinham mais ou menos estáveis com média superior a 4.500 registros mensais [em nível nacional] caem abruptamente a partir do final de fevereiro. Em março a redução é de $12,6 \%$ e em abril chega a cair $21,7 \%$ em relação ao mês anterior. No mês de abril são registrados pouco mais de 3.200 casos de estupro e estupro de vulnerável, muito abaixo da média verificada ao longo da série. A partir de maio, no entanto, os números voltaram a crescer retomando o patamar do ano anterior, com média de 5 mil casos em agosto.
\end{abstract}

Essa retomada ao quadro comum de estabilidade de altos casos de violência contra a mulher podem ser atribuído à perda do medo da população da contaminação com o vírus COVID-19 e o crescimento de $1,2 \%$ em maio do volume de prestação de serviços (SILVEIRA e ALVARENGA, 2021). Essa sensação de normalidade social, motivadas pela minimização do COVID-19 por parte do presidente Jair Messias Bolsonaro, pode ter justificado a incidência do crime em outras esferas além do ambiente doméstico e a conclusão de denúncias posterior.

Assim, Mato Grosso do Sul, durante todo o ano de 2020, aponta uma incidência de 68,9 crimes de violência sexual por 100 mil habitantes (FÓRUM BRASILEIRO DE SEGURANÇA PÚBLICA, 2020, p. 112 ), incluindo os casos de estupro e de estupro de vulnerável, podendo ou não ocorrer em ambiente de isolamento social e sendo ou não um quadro progressivo iniciado pela violência doméstica.

Devido a essa diminuição do alcance das políticas públicas, o Estado de Mato Grosso do Sul disponibilizou sites tais como o 'Não se Cale' (2020) e o aplicativo MS Digital, no ícone Mulher MS, com o objetivo de divulgar orientações sobre casos de violência doméstica e feminicídio ocorridos durante a quarentena e como combatê-la e/ou pedir ajuda.

\title{
METODOLOGIA
}

Devido ao momento atual onde se persevera medidas de isolamento social, a metodologia do presente estudo consiste no levantamento de dados disponibilizados por órgãos federais tais como a Secretaria de Estado de Justiça e Segurança Pública do Estado de Mato Grosso do Sul (SEJUSP) e Ministério Público de Mato Grosso do Sul para que, após o recolhimento dos dados, se levante uma análise dedutiva que explique o fenômeno observado.

Considerando-se que, segundo o IBGE (2021), o estado de Mato Grosso do Sul (Figura 2) conta atualmente com uma área territorial de $357.147,994 \mathrm{~km}^{2}$ e uma população estimada, no Censo de 2010, de 2.809.394, onde se conta qual uma densidade demográfica de $6,86 \mathrm{hab} / \mathrm{km}^{2}$ e que o novo fenômeno de pandemia retarda a computação oficial de dados, se buscou averiguar mídias online do próprio estado para compor o presente trabalho. 
Figura 2: Localização do Estado de Mato Grosso do Sul.

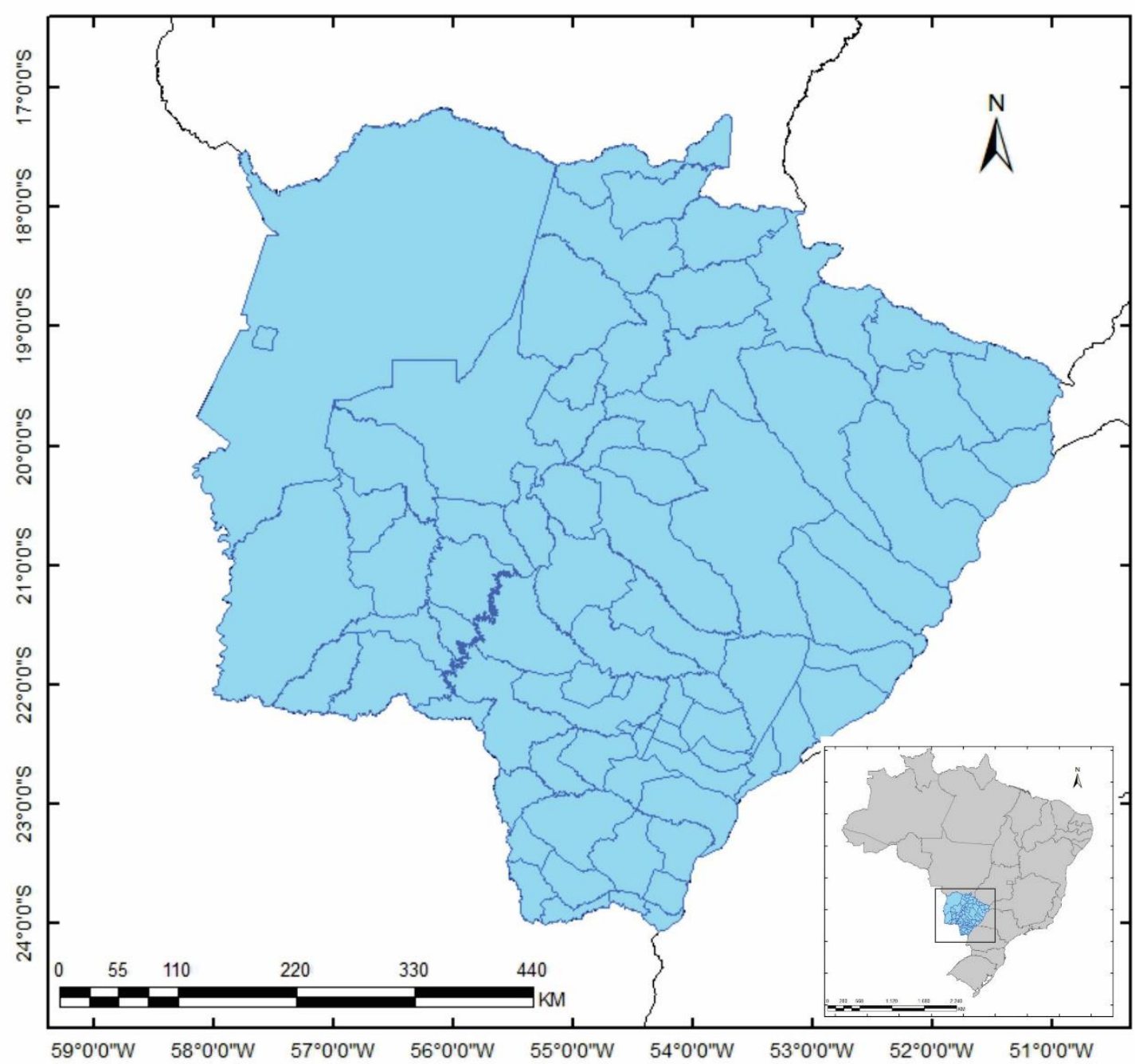

Fonte: IBGE (2021).

Também foram consultados os seguintes jornais: Correio do Estado, Dossiê Violência Contra as Mulheres, G1, Não se Cale e Perfil News.

\section{RESULTADO E DISCUSSÃO}

No Brasil, 1.350 mulheres foram vítimas do crime em 2020, alta de $0,7 \%$ na comparação com 2019 , quando 1.330 mulheres morreram em decorrência de feminicídio (figura 3).

Dados do Mapa do Feminicídio de Mato Grosso do Sul mostram que 2020 foi o ano com maior número de registros de feminicídios no Estado, desde 2015, quando o código penal foi alterado e o feminicídio passou a ser considerado como crime hediondo. Em todos os meses de 2020, Mato Grosso do Sul registrou esse tipo de crime. Em 2020, um ano atípico de pandemia, foram 40 casos - um aumento de $33,33 \%$, já que em 2019 foram 30 vítimas, o que preocupa toda a rede de enfrentamento à violência contra mulheres e autoridades que atuam nas políticas públicas para mulheres (Figura 4). 
Figura 3: Vítimas de feminicídio no Brasil (2016-2020).

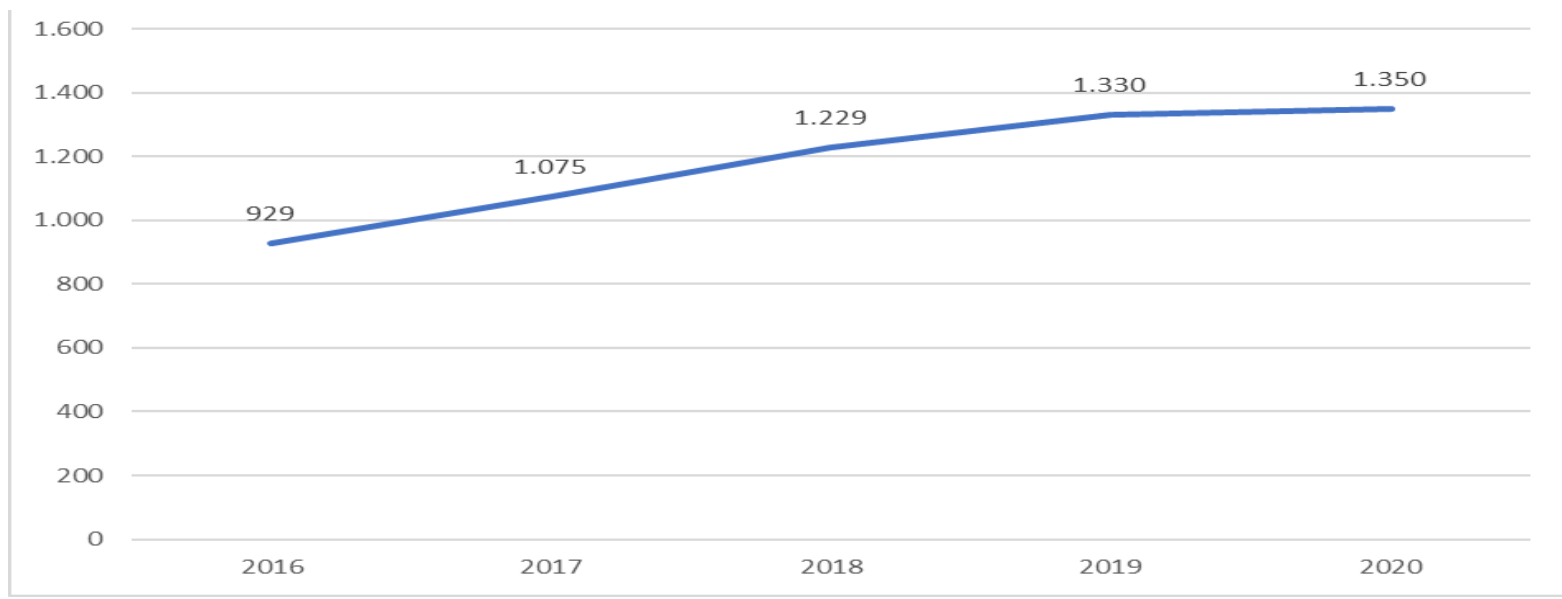

Fonte: Secretarias Estaduais de Segurança Pública e/ou Defesa Social; Fórum Brasileiro de Segurança Pública.

Figura 4: Vítimas de feminicídio no Mato Grosso do Sul (2015-2020).

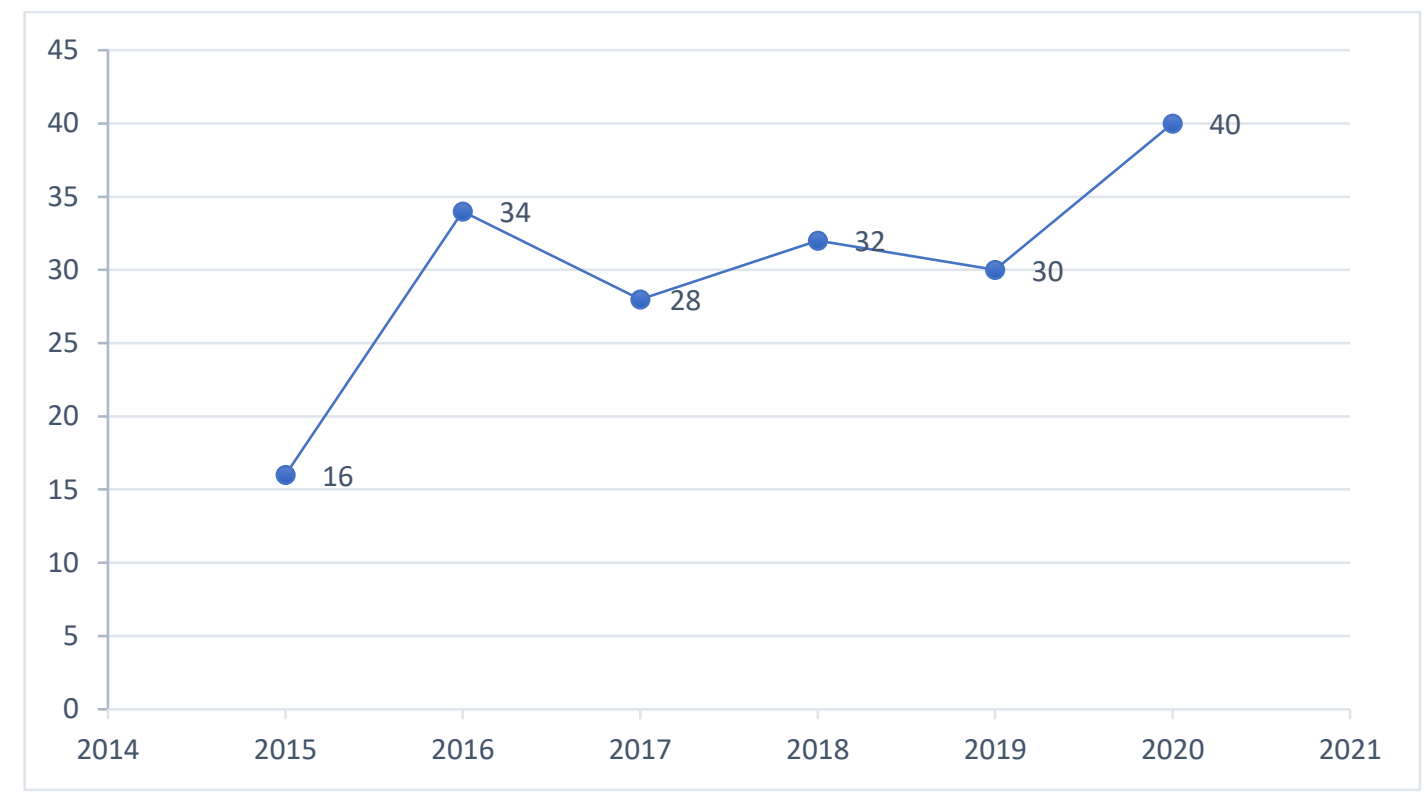

Fonte: MATO GROSSO DO SUL, 2021.

Considerando o fato de que, de acordo com Fernandes (2016, p. 37 e 39),

[Mato Grosso do Sul], [...] evidenciou que os atos de violência cometidos contra as mulheres ocorrem com maior frequência entre as mulheres jovens e adultas, brancas, casadas ou com união estável e com baixo nível de escolaridade. [...]Em Campo Grande se foi identificado que a raça/cor mais frequente entre as mulheres vítimas de violência foi a branca com $26,1 \%$, seguida pela parda com $24,5 \%$ e pela preta com $23,7 \%$.

Carvalho $(2010$, p. 57$)$ apud Ramos $(2018$, p. 1) afirma que as mulheres vítimas de maus tratos percepcionam "que, em termos de personalidade, essas passaram a ser mais ansiosas, desconfiadas, com um nível de preocupação superior e ainda mais dependentes".

Ao caso das vítimas que sejam mães, se evidencia que a violência ocorrida entre os pais pode gerar filhos agressivos e delinquentes, uma vez que a agressão é vista como um fator neutral. Fora tal, os filhos estão sujeitos a desenvolver as mesmas sequelas físicas e psicológicas semelhantes à própria vítima (SANTOS e MORÉ, 2011, p. 1).

\begin{tabular}{llllll}
\hline Hygeia Uberlândia - MG & Edição especial: X GeoSaude & Fev./2022 & p. 61-73 Página 66
\end{tabular}


Isso ocorre uma vez que, de acordo com Kitzmann (2007, p. 2), a resposta comportamental da criança é algo adaptativo ao contexto da violência familiar, desajustados em outros contextos. Esse desajustamento ocorre, pois, a criança não cresce com a percepção adequada sobre como reagir ao presenciar uma agressão, podendo crescer com a propensão de se utilizar a violência para resolução de conflitos ou com a crença de que são responsáveis pelos conflitos em seu ambiente doméstico.

Segundo a Redação (2021)

Diante do isolamento social, cada vez mais crianças e adolescentes testemunham a morte ou espancamento de suas mães, avós ou cuidadoras. Mas sem critérios definidos e padronizados para quantificar os casos, essa percepção de crescimento no número de crianças e adolescentes afetadas pela violência doméstica durante a pandemia é apenas uma "observação" de quem trabalha constantemente no atendimento dos casos.

Fora isso, a informação pode ser considerada um dado empírico uma vez que não entra nas estatísticas oficiais, apenas em outras etapas de investigação. Portanto é impreciso se catalogar o crescimento dos casos dos filhos que presenciam esse quadro.

Conforme a explicação do Centro de Referência Especializado de Assistência Social (CREAS) de Chapadão do Sul/MS, o procedimento direcionado a uma criança testemunha de assassinato ou órfã em decorrência a própria é encaminhada pela justiça para o atendimento multidisciplinar

Com a assistência social e de saúde. A prioridade tem sido já direcionar a criança para acompanhamento psicológico e, quando necessário, psiquiátrico. Também [se há a realização de] uma força-tarefa para que a coleta desse depoimento, caso ela precise realmente ser feita, seja assistida por toda a equipe, na intenção da criança não precisar ficar repetindo esse depoimento e revivendo o trauma durante as investigações (SANTANA, 2021).

Kitzmann (2007, p.2) demonstra como se há maior probabilidade de incidência de violência doméstica em lares com filhos, sobretudo os menores de 5 anos. A problemática reside no fato de que essas crianças podem crescer com problemas psicossociais semelhantes às vítimas de abuso físico uma vez que o terror permeia a infância do sujeito perturbando significativamente sua socialização. Especialistas consideram inclusive a exposição à violência doméstica como uma forma de maus-tratos psicológicos.

Vasconcelos et. al (2020, p. 76) aponta que

A rápida progressão da epidemia e o excesso de informações disponíveis, por vezes contraditórias, é um campo facilitador para mudanças comportamentais impulsionadoras de adoecimento psicológico (Qian et al., 2020; Lima et al.l, 2020). Pode-se dizer que junto a pandemia do novo coronavírus surge um estado de pânico social global e a sensação de isolamento desperta angústia, insegurança, medo de que podem se prolongar até mesmo após o controle do vírus (Hossain et al., 2020).

Por esse motivo, e ao medo de contração do vírus e transmissão aos filhos, muitas mulheres deixam de dar início à denúncia contra seus agressores e àquelas que dão abertura geralmente não dão continuidade, pois muitas vezes também se há a desinformação propositalmente premeditada pelo agressor que delegacias e outros órgão de apoios encontram-se fechadas de acordo com a fase restritiva do momento.

Além do mais, segundo a mídia Perfil News,

um estudo divulgado [...] pela Delegacia-Geral da Polícia Civil e pela Subsecretaria de Políticas Públicas para Mulheres (SPPM) mostrou que quase $80 \%$ das mulheres vítimas de feminicídio em Mato Grosso do Sul no ano passado perderam a vida dentro de casa (BERTO, 2020, p. 1).

De acordo com o site do governo do Estado, partir da fala da subsecretária Estadual de Políticas Públicas para Mulheres, Luciana Azambuja, que "em 2020, período atípico em vários pontos devido à pandemia, o número de feminicídio aumentou 120\% em relação a 2019, em Campo Grande, com 11 mortes e uma elevação de $30 \%$ em todo o Estado". Ademais, afirma que casos de violência doméstica também apresentaram aumento na quarentena a partir da tentativa não concluída do feminicídio, do crime de ameaça e do estupro. Ambos se deram devido a limitação de comunicação e mobilidade da vítima (GOVERNO DO ESTADO DE MATO GROSSO DO SUL, 2021a e b, p. 1).

Contraditoriamente, se há a disponibilização de dados pelo Fórum Brasileiro de Segurança Pública (2021, p. 101) que demonstram que, em números absolutos, Mato Grosso do Sul registrou uma queda de quadros de lesão corporal dolosa dentro da especificidade de violência doméstica em relação a

$\begin{array}{lllll}\text { Hygeia Uberlândia - MG } & \text { Edição especial: X GeoSaude } & \text { Fev./2022 } & \text { p. 61-73 } & \text { Página } 67\end{array}$


2019 com 5.111 ocorrências e 2020 com 4.778. Se reforça que a lesão corporal dolosa praticada em contexto doméstico pode se referir a qualquer ato de violência física praticado contra a mulher dentro de seu ambiente familiar.

A mídia Correio do Estado reforça que,

No ano passado [2020], foram registrados 5.755 casos de violência doméstica contra mulheres; 407 estupros; 86 de importunação sexual; 14 de feminicídio tentado; 11 de feminicídio consumados e outros (1.055) (CAMARGO, 2021, p. 1).

Inclusive dados disponibilizados pelo Fórum Brasileiro de Segurança Pública (2021, p. 90), mostram que, em números absolutos, o estado de Mato Grosso do Sul registrou 30 casos de feminicídio em 2019 ao passo que em 2020 se registrou 43 casos de feminicídio. Ainda segundo a mesma fonte, se aponta que, em números absolutos, em 2019 o estado registrou 84 tentativas de feminicídio enquanto em 2020 se registra 54 tentativas de feminicídio, podendo-se concluir, portanto, que no período de isolamento social se houve um acréscimo na conclusão do feminicídio.

O número de feminicídios cresceu 41,7\% entre 2019 e 2020 em Mato Grosso do Sul, segundo o Anuário Brasileiro de Segurança Pública, divulgado pelo Fórum Brasileiro de Segurança. Foram 43 ocorrências do tipo no ano passado e 30 no período anterior. Além disso a taxa de homicídios femininos foi a mais alta do País em 2020, com 7,8 por 100 mil mulheres, enquanto a média do País foi de 3,6 por 100 mil mulheres. As maiores taxas de feminicídio nesse período de isolamento ocorreram em Mato Grosso, Roraima e Mato Grosso do Sul, onde os dois últimos dividem a segunda maior taxa nacional com uma taxa de feminicídio de 3 por 100 mil mulheres. Fora isso, Mato Grosso do Sul registrou uma taxa elevada de homicídio feminino de 7,8, onde também se inclui os casos de feminicídio junto ao homicídio feminino, conforme se observa na figura 4 (ANUÁRIO BRASILEIRO DE SEGURANÇA PÚBLICA, 2021, p. 95).

Figura 4: Taxa de homicídios femininos e feminicídios, por UF. Brasil (2020).



Fonte: ANUÁRIO BRASILEIRO DE SEGURANÇA PÚBLICA (2021, p. 95).

Dados do Mapa de Feminicídio de 2020 de Mato Grosso do Sul (SECICMS, 2021, p. 13), demonstram que houve a ocorrência de 12 feminicídios na capital de Campo Grande; seguido por 3 casos em Costa Rica e Dourados; 2 casos em Anastácio e Três Lagoas; e 1 caso em Água Clara, Amambai, Aquidauana, Bonito, Cassilândia, Chapadão do Sul, Corumbá, Coxim, Fátima do Sul, Japorã, Jardim, Laguna Caarapã, Nova Alvorada do Sul, Nova Andradina, Paranaíba, Rio Brilhante, São Gabriel do Oeste e Sidrolândia. Os demais municípios não possuem registros catalogados da incidência do crime.

Das informações que se há registros de feminicídios ocorridos em período pandêmico, cerca de $77,5 \%$ dos casos de feminicídio foram cometidos nas residências e $82,9 \%$ dos casos ocorreram em áreas urbanas. Ademais, $47,5 \%$ das mortes ocorreram por armas brancas enquanto $30 \%$ ocorreram por arma de fogo (MATO GROSSO DO SUL, 2021, p. 15). Já no Brasil 55,1\% das mortes ocorreram por armas brancas e 26,6\% ocorreram por arma de fogo, conforme figura 5. 
Figura 5: Feminicídios e demais mortes violentas intencionais de mulheres, por instrumento empregado Brasil (2020).

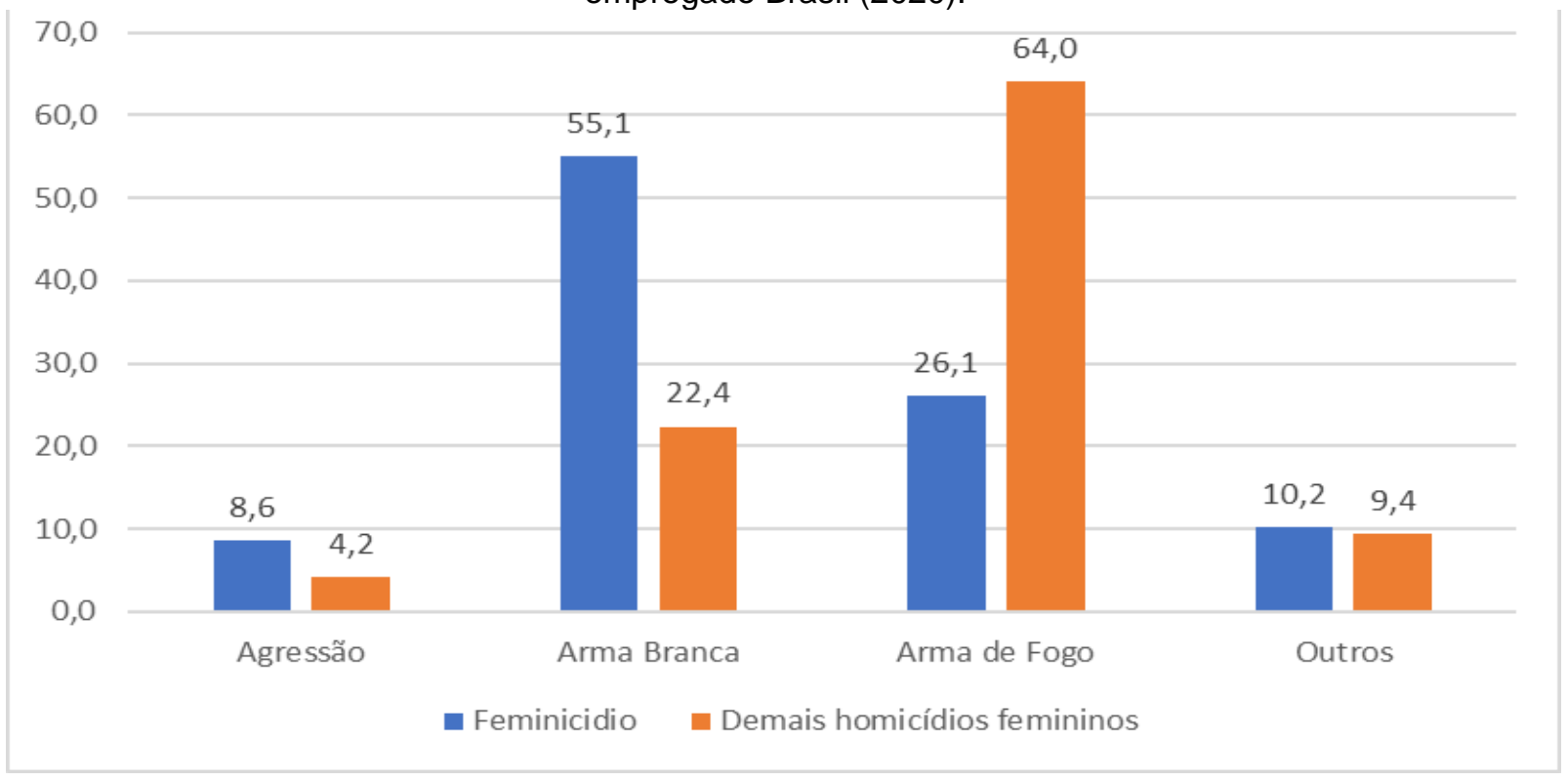

Fonte: ANUÁRIO BRASILEIRO DE SEGURANÇA PÚBLICA (2021, p. 100).

Os dados ficam mais preocupantes quando se notifica que em 2020 se foi registrado 186.071 novas armas no Brasil, ou seja, um aumento de $97,1 \%$ em relação ao ano anterior. É possível contabilizar que atualmente se há 2.077.126 exemplares na sociedade civil, isto é, uma arma para cada 100 brasileiros (VENDRUSCOLO, 2021). A aquisição foi facilitada pelos esforços do presidente Jair Messias Bolsonaro naquilo que tange novas regras para o Estatuto do Desarmamento (Lei n. 10,826/2003) para o afastamento do controle do Exército sobre a aquisição e o registro de alguns armamentos e equipamentos e a que permite o porte simultâneo de até duas armas de fogo por cidadãos (VERDÉLIO, 2021).

Ainda segundo Vendruscolo (2021), se houve o aumento das mortes violentas após as ações de flexibilização de porte de arma. $O$ quadro de violência de gênero e contra crianças e adolescentes tornou-se preocupante, sobretudo em período de isolamento social para contenção do Covid-19. O aumento do tempo em ambiente violento e o temor do agressor armado forçou com que muitas vítimas optassem pelo silêncio. Assim, citando Vendruscolo (2021) demonstra que os dados relativos de mortes violentas impedem a subnotificação do quadro de violência.

Entre março e maio de 2020 , houve um aumento de $34 \%$ das mortes violentas desse grupo em relação aos mesmos meses do ano anterior. Isso indica que a violência não diminuiu e sim que foi subnotificada (VENDRUSCOLO, 2021). A queda dos registros de lesão corporal por violência doméstica também é contraditória ao aumento nas concessões de medidas protetivas de urgência e da procura ao número 190 da Polícia Militar.

Em relação aos horários de ocorrência, o feminicídio, em Mato Grosso do Sul no ano de 2020, foi concluído, em sua maioria, entre 00h e 6:59 da manhã $(41,5 \%)$ e entre $18 \mathrm{~h}$ e $00 \mathrm{~h}$ (29\%) (MATO GROSSO DO SUL, 2021, p. 16). No Brasil o maior número de casos ocorre a noite e na madrugada com 49,8\%, conforme se observa na Figura 6 . 
Figura 6: Feminicídios e demais mortes violentas intencionais de mulheres, por período da ocorrência Brasil (2020).

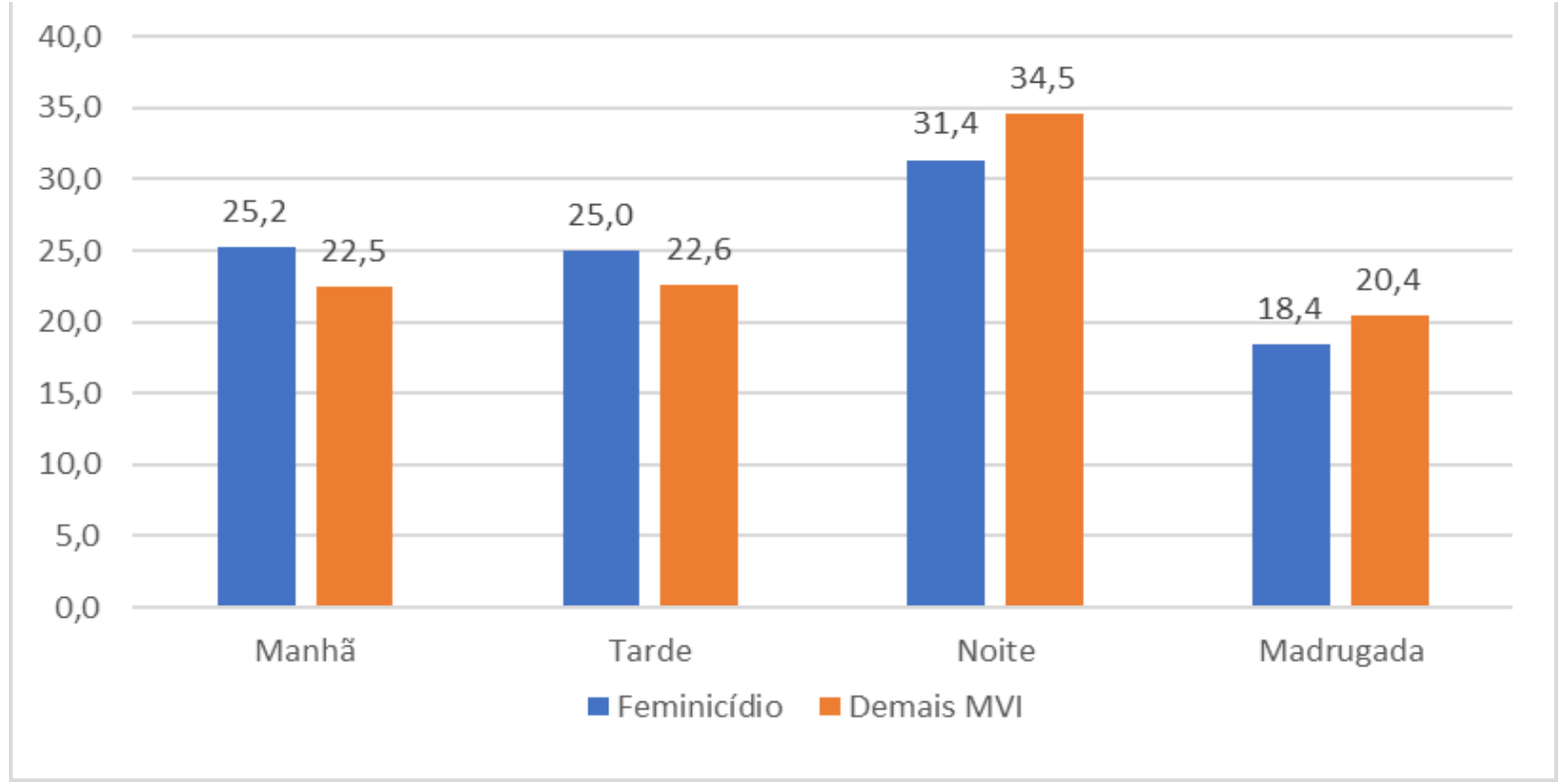

Fonte: ANUÁRIO BRASILEIRO DE SEGURANÇA PÚBLICA (2021, p. 99).

A partir do levantamento dos dados, o estado de Mato Grosso do Sul passou a reforçar as atividades da Casa da Mulher em sua Delegacia Especializada de Atendimento à Mulher (Deam) a partir da implementação de um núcleo do IMOL - Instituto de Medicina e Odontologia Legal da Coordenadoria Geral de Perícias.

A ininterrupção de atividades teve a pretensão de garantir a agilidade necessária ao socorro das vítimas aonde médicos legistas estejam à disposição das próprias.

O ano de 2020 também foi o ano que se tornou necessário a inauguração da Sala Lilás de Maracaju. A Sala Lilás é um espaço voltado exclusivamente para o atendimento às crianças, meninas e mulheres vítimas de violência sexual e de violência doméstica para receberem acolhimento especializado em ambiente de conforto e privacidade (SEICMS, 2020, p. 28).

Inclusive, a subsecretaria de Políticas Públicas para a Mulher do Governo do Estado, em parceria com a Secretaria de Governo e Secretaria de Justiça Pública, definiram a atualização do Mapa do Feminicídio, da edição de 2021, para dia 1 de junho de 2021.

A ideia é que se adicione novos indicadores da violência contra a mulher, a partir da inclusão de elementos contundentes como fogo ou asfixia como instrumento específico de agressão e assassinato; objetificação do corpo feminino; condição de etnia; análise crimes sexuais; entre outras informações.

As estatísticas trazidas pelo Mapa comprovam que na maioria dos casos, as mulheres foram mortas nos locais onde mais deveriam se sentir seguras, em suas residências. As mortes ocorreram pelas mãos de seus companheiros ou ex-companheiros, que não aceitavam o fim do relacionamento ou manifestavam sentimento de posse e de objetificação em relação à mulher.

Entre janeiro e maio de 2021, em Mato Grosso do Sul um total de 14 mulheres foram vítimas de feminicídio, segundo dados da Secretaria de Políticas Públicas para as Mulheres. De acordo com dados do Anuário de Segurança Pública, do FBSP (Fórum Brasileiro de Segurança Pública) o Estado tem a segunda maior taxa de feminicídio de todo o Brasil, empatado com Roraima. Segundo o Anuário, os dois estados registraram 3 crimes a cada 100 mil habitantes.

Mas o que se constatou no presente estudo é que $93,33 \%$ das vítimas não tinham nenhuma medida protetiva contra o autor do seu feminicídio. Essas mulheres morreram em silêncio, sem acionar nenhum serviço público de atenção à mulher em situação de violência, sem ajuda de profissionais especializadas, sem qualquer orientação que pudesse tê-las tirado do ciclo de violência e permitido que reconstruíssem suas vidas. É preciso reforçar o alerta para as denúncias dos casos de violência contra a mulher. Pode ser difícil para a mulher que convive com o agressor se perceber como vítima e mais

$\begin{array}{llllll}\text { Hygeia Uberlândia - MG } \quad \text { Edição especial: X GeoSaude } & \text { Fev./2022 } & \text { p. 61-73 Página } 70\end{array}$


difícil ainda denunciar a pessoa com quem mantém laços de afeto e afinidade. Não julgue uma mulher em situação de violência que ainda não está encorajada a romper o relacionamento.

\section{CONSIDERAÇÕES FINAIS}

A partir da análise dos dados disponibilizados acerca da condição do estudo no estado de Mato Grosso do Sul, constatou-se como o ambiente familiar pode abrigar esses cenários de violência propiciando, também, seu último estágio de violência pelo feminicídio como a morte praticada contra a vítima mulher.

A violência de gênero é uma violência histórica e estrutural, que deve ser vista não somente como uma questão de justiça e segurança, mas também como uma questão de saúde pública, de educação e, principalmente, de cidadania.

Neste contexto, apesar do Estado de Mato Grosso do Sul ter atuado com firmeza para prevenir e erradicar a violência contra mulheres e meninas, o enfrentamento à violência de gênero é o grande desafio de todos os governos.

Assim, em mais uma ação de proteção às mulheres vítimas de violência doméstica e familiar, em agosto de 2021 foi sancionada a Lei ${ }^{\circ}$ 5.703, que institui no Estado de Mato Grosso do Sul a campanha "Sinal Vermelho" como mecanismo de combate e prevenção à violência doméstica e familiar prevista na Lei № 11.340, de 7 de agosto de 2006.

Desta forma, espera-se que a divulgação e disponibilidade de todos esses mecanismos de proteção e apoio às mulheres possam efetivamente protegê-las dessa forma de violência tão arcaica e arraigada na sociedade, em especial a violência doméstica tema deste trabalho.

\section{AGRADECIMENTOS}

Agradeço a Universidade Federal de Mato Grosso do Sul por me propiciar as condições favoráveis para meu desenvolvimento acadêmico e ao evento do X Simpósio Nacional de Geografia da Saúde pela oportunidade de apresentação e publicação.

\section{REFERÊNCIAS}

ALVARENGA D.; SILVEIRA, D. Setor de serviços cresce $1,2 \%$ em maio e volta a superar nível pré-pandemia. G1. 13 jul. 2021. Disponível em: https://g1.globo.com/economia/noticia/2021/07/13/setor-de-servicos-cresce-12percent-em-maiomostra-ibge.ghtml.

\section{ALVES, E. COVID-19: mulheres enfrentam em casa a violência doméstica e a pandemia do novo coronavírus. Ministério Público de Mato Grosso do Sul. 7 ago. 2020. Disponível em: https://www.mpms.mp.br/noticias/2020/08/covid-19-mulheres-enfrentam-em-casa-a-violencia- domestica-e-a-pandemia-do-novo-coronavirus.}

MATO GROSSO DO SUL. Mapa do feminicídio - Mato Grosso do Sul. Governo do Estado de Mato Grosso do Sul. Jul. 2020. Vol. 1. p. 1-34. Disponível em: https://abmcj.ong.br/wpcontent/uploads/2020/12/MAPA-DO-FEMINICI\%CC\%81DIO.pdf.

BANDEIRA, L. Feminicídio: a última etapa do ciclo da violência contra a mulher, por Lourdes Bandeira. Dossiê Violência Contra as Mulheres. 11 out. 2013. Disponível em: http://www.compromissoeatitude.org.br/feminicidio-a-ultima-etapa-do-ciclo-da-violencia-contra-amulher-por-lourdes-bandeira/.

\section{BELCHIOR, J.; MACHADO, J. Mato Grosso do Sul reduz índices de violência durante a} pandemia. Sejusp-MS. 25 out. 2020. Disponível em: https://www.sejusp.ms.gov.br/mato-grosso-dosul-reduz-indices-de-violencia-durante-a-pandemia/.

BRASIL. Lei no 11.340, de 7 de agosto de 2006. Presidência da República. Secretaria-Geral. Subchefia para Assuntos Jurídicos. 2006. Disponível em: http://www.planalto.gov.br/ccivil_03/_Ato2004-2006/2006/Lei/L11340.htm.

$\begin{array}{lllll}\text { Hygeia Uberlândia - MG } \quad \text { Edição especial: X GeoSaude } & \text { Fev./2022 } & \text { p. 61-73 } & \text { Página } 71\end{array}$


BRASIL. Lei no 13.104, de 9 de março de 2015. Presidência da República. Secretaria-Geral. Subchefia para Assuntos Jurídicos. 2015. Disponível em: http://www.planalto.gov.br/ccivil_03/_ato2015-2018/2015/lei/113104.htm.

CAMARGO, N. Em 2020, quase 6 mil mulheres foram vítimas de violência doméstica. Correio do Estado. 3 fev. 2021. Disponível em: https://correiodoestado.com.br/cidades/2020quase-6-milmulheres-foram-vitimas-de-violencia-em-casa/382062.

FERNANDES, C. O. Situação da violência contra a mulher de casos notificados nos serviços de saúde de Campo Grande-MS. UFMS. Campo Grande, 2016. p. 10-69. Disponível em: https://inisa.ufms.br/files/2019/08/Situa\%C3\%A7\%C3\%A3o-de-viol\%C3\%AAncia-contra-mulher-decasos-notificados-nos-servi\%C3\%A7os-de-sa\%C3\%BAde-de-Campo-Grande-MS.pdf.

FÓRUM BRASILEIRO DE SEGURANÇA PÚBLICA. Anuário Brasileiro de Segurança Pública. Brasil, 2021, ano 15. p. 2-380.

GALVANI, G. Violência doméstica na quarentena: como se proteger de um abusador? Carta Capital. 29 mar. 2020. Disponível em: https://www.cartacapital.com.br/saude/violencia-domestica-naquarentena-como-se-proteger-de-um-abusador/.

GOVERNO DO ESTADO DE MATO GROSSO DO SUL. Site "Não se Cale" do Governo MS é ferramenta de combate à violência contra as mulheres. Portal do Governo de Mato Grosso do Sul. Subsecretaria de Estado de Políticas para Mulheres (SPPM). 6 jun. 2020. Disponível em: http://www.ms.gov.br/governo-do- GOVERNO DO ESTADO DE MATO GROSSO DO SUL. estadolanca-o-site-nao-se-cale-sobre-violencia-contra-as-mulheres/.

GOVERNO DO ESTADO DE MATO GROSSO DO SUL. Novo Mapa do Feminicídio, edição 2021a, contará com novos indicadores da violência contra a mulher. 9 fev. 2021. Portal do Governo de Mato Grosso do Sul. Disponível em: http://www.ms.gov.br/novo-mapa-do-feminicidio-edicao-2021-contaracom-novos-indicadores-da-violencia-contra-a-mulher/.

GOVERNO DO ESTADO DE MATO GROSSO DO SUL. Subsecretária apresenta ações contra feminicídio e fala da implantação do IMOL na Casa da Mulher Brasileira. 3 fev. 2021b. Portal do Governo de Mato Grosso do Sul. Disponível em: http://www.ms.gov.br/subsecretaria-apresentaacoes-contra-feminicidio-e-fala-da-implantacao-do-imol-na-casa-da-mulher-brasileira/.

KITZMANN, K. M. Violência doméstica e seu impacto sobre o desenvolvimento social e emocional de crianças pequenas. Enciclopédia sobre o Desenvolvimento na Primeira Infância. 2007, Éd. Rév. CEDJE.

MATO GROSSO DO SUL. Mapa do feminicídio: Mato Grosso do Sul. SPPM. SECIC. Mato Grosso do Sul, 2021. Volume II. Disponível em: https://www.naosecale.ms.gov.br/wpcontent/uploads/2021/06/MAPA-DO-FEMINICIDIO-2020.pdf.

MATO GROSSO DO SUL. Lei № 5613 de 10 de dezembro de 2020. Dispõe sobre a implementação de medidas eficazes para prevenção da covid-19 e para a maior proteção às mulheres e crianças vítimas de violência doméstica, durante o período de estado de calamidade, decretado em razão da pandemia de covid-19. Disponível em: https://www.legisweb.com.br/legislacao/?id=405766. Acesso em 25 abr. 2021.

IBGE. Mato Grosso do Sul. 2020. Disponível em: https://www.ibge.gov.br/cidades-eestados $/ \mathrm{ms}$.html.

JESUS, V.; SANTOS, E. T. A comunicação do feminicídio na perspectiva dos jornais online no município de Aquidauana e Anastácio/MS, no período de 2015 a 2020. 2020. Disponível em: https://drive.google.com/file/d/13vCEuMfClzM-Ec-LaFqtS7EJzj6Ml6Jh/view.

Linha do tempo do Coronavírus no Brasil. Sanar Saúde. Disponível em: https://www.sanarmed.com/linha-do-tempo-do-coronavirus-no-brasil.

LOBO, J. C.. Uma outra pandemia no Brasil: as vítimas da violência doméstica no isolamento social e a "incomunicabilidade da dor". TESSITURAS. Revista de Antropologia e Arqueologia. V8. S1. JAN-JUN 2020. Pelotas, RS. p. 21-26.

MARQUES, E. S.; MORAES, Claudia Leite de; HASSELMANN, Maria Helena; DESLANDES, Suely Ferreira; REICHENHEIM, Michael Eduardo. A violência contra mulheres, crianças e adolescentes em tempos de pandemia pela COVID-19: panorama, motivações e formas de enfrentamento.

$\begin{array}{llllll}\text { Hygeia Uberlândia - MG } & \text { Edição especial: X GeoSaude } & \text { Fev./2022 } & \text { p. 61-73 Página } 72\end{array}$ 
ESPAÇO TEMÁTICO: COVID-19 - CONTRIBUIÇÕES DA SAÚDE COLETIVA. Cad. Saúde Pública. 2020. Disponível em: https://www.scielosp.org/article/csp/2020.v36n4/e00074420/.

https://doi.org/10.1590/0102-311 ×00074420

OBANDO, M. Lei amplia medidas de prevenção e acolhimento para casos de violência doméstica na pandemia. Portal do Governo de Mato Grosso do Sul. 11 dez. 2020. Disponível em: http://www.ms.gov.br/lei-amplia-medidas-de-prevencao-e-acolhimento-para-casos-de-violenciadomestica-na-pandemia/.

QUIRINO, F. Região Centro-Oeste: violência contra mulher aumenta na pandemia. MST. 30 nov. 2020. Disponível em: https://mst.org.br/2020/11/30/regiao-centro-oeste-violencia-contra-mulheraumenta-na-pandemia/.

RAMOS, P. Qual o perfil das mulheres vítimas de violência conjugal? 21 ago. 2018. Disponível em: https://www.megajuridico.com/qual-o-perfil-das-mulheres-vitimas-de-violencia-conjugal/.

REDAÇÃO. Na pandemia, três mulheres foram vítimas de feminicídios por dia. Amazônia Real. 8 mar. 2021. Disponível em: https://amazoniareal.com.br/na-pandemia-tres-mulheres-foram-vitimas-defeminicidios-por-

dia/?gclid=CjwKCAiAp8iMBhAqEiwAJb94z1VKh8yaXfL9BqF6XElu5R1WgitnMybVzj02Tfb2keYmxgV MHhLb1hoC9S0QAvD_BwE.

SANTANA, J. Filhos da violência de gênero: como crianças e adolescentes são afetados pela violência doméstica. 8 mar. 2021. Disponível em: https://azmina.com.br/reportagens/filhos-violenciagenero-pandemia/.

SANTOS, A. C. W..; MORÉ, C. L. O. O. Impacto da violência no sistema familiar de mulheres vítimas de agressão. Psicol. Cienc. Prof. Vol. 31. No. 2. Brasília, 2011.

https://doi.org/10.1590/S1414-98932011000200003

SECICMS. Secretaria de Estado de Cidadania e Cultura. Violência doméstica e familiar contra mulheres em números. GOVERNO DO ESTADO DE MATO GROSSO DO SUL. Subsecretaria Especial de Cidadania (SECID/MS). 11 set. 2020. Disponível em:

https://www.secid.ms.gov.br/violencia-domestica-e-familiar-contra-mulheres-em-numeros/.

VASCONCELOS, C. S. S; FEITOSA, I. O.; MEDRADO, P. L. R.; BRITO, A. P. B. O novo

coronavírus e os impactos psicológicos da quarentena. Revista Desafios v. 7, n. Supl. COVID-19. 22 abr. 2020. P. 76-80. Disponível em:

https://sistemas.uft.edu.br/periodicos/index.php/desafios/article/view/8816/16731.

https://doi.org/10.20873/uftsuple2020-8816

VENDRUSCOLO, S. Brasil duplica o número de armas de fogo nas mãos da população em três anos. El País. 15 jul. 2021. Disponível em: https://brasil.elpais.com/brasil/2021-07-15/brasil-duplica-onumero-de-armas-de-fogo-nas-maos-da-populacao-em-tres-anos.html.

VERDÉLIO, A. Entra em vigor parte dos decretos que ampliam acesso a armas de fogo. Agência Brasil. 13 abr. 2021. Disponível em: https://agenciabrasil.ebc.com.br/geral/noticia/2021-04/entra-emvigor-parte-dos-decretos-que-ampliam-acesso-armas-de-fogo. 